Published in final edited form as:

ACS Catal. 2016 November 4; 6(11): 7810-7813. doi:10.1021/acscatal.6b02550.

\title{
Highly Stereoselective Biocatalytic Synthesis of Key Cyclopropane Intermediate to Ticagrelor
}

\author{
Kari E. Hernandez ${ }^{\dagger}$, Hans Renata ${ }^{\dagger} \S$, Russell D. Lewis ${ }^{\ddagger}$, S. B. Jennifer Kan ${ }^{\dagger}$, Chen Zhang ${ }^{\Uparrow}$,

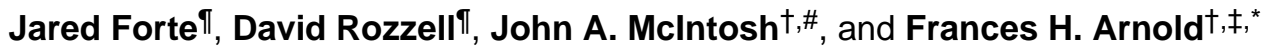 \\ tDivision of Chemistry and Chemical Engineering, California Institute of Technology, Pasadena, \\ CA, 91125, United States \\ ‡Biology and Biological Engineering, California Institute of Technology, Pasadena, CA, 91125, \\ United States \\ IProvivi, Inc., Santa Monica, CA, 90404, United States
}

\begin{abstract}
Extending the scope of biocatalysis to important non-natural reactions such as olefin cyclopropanation will open new opportunities for replacing multi-step chemical syntheses of pharmaceutical intermediates with efficient, clean, and highly selective enzyme-catalyzed processes. In this work, we engineered the truncated globin of Bacillus subtilis for the synthesis of a cyclopropane precursor to the antithrombotic agent ticagrelor. The engineered enzyme catalyzes the cyclopropanation of 3,4-difluorostyrene with ethyl diazoacetate on a preparative scale to give ethyl-(1 $R, 2 R)$-2-(3,4-difluorophenyl)-cyclopropanecarboxylate in 79\% yield, with very high diastereoselectivity ( $>99 \% \mathrm{dr}$ ) and enantioselectivity (98\% ee), enabling a single-step biocatalytic route to this pharmaceutical intermediate.
\end{abstract}

\section{Graphical Abstract}

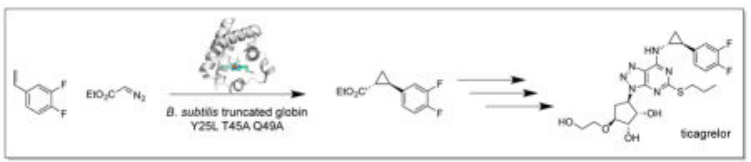

\section{Keywords}

biocatalysis; directed evolution; ticagrelor; cyclopropanation; Bacillus subtilis; truncated globin

\footnotetext{
*Corresponding author: frances@ caltech.cheme.edu (Frances H. Arnold).

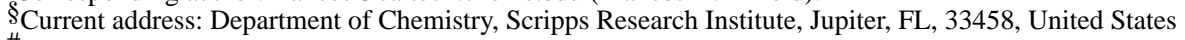

\#Current address: Merck, Kenilworth, NJ, 07033, United States

Caltech and FHA have a financial ownership interest in Provivi, Inc., the company sponsoring this research through the National Science Foundation STTR Program. FHA and Caltech may benefit financially from this interest if the company is successful in making product(s) that is/are related to this research. The terms of this arrangement have been reviewed and approved by Caltech in accordance with its conflict of interest policies.

Supporting information available: experimental procedures, standard curves, and characterization of ticagrelor cyclopropyl ester $(R, R)$-5. This material is available free of charge via the Internet at http://pubs.acs.org.
} 
Ticagrelor (1) is a $\mathrm{P} 2 \mathrm{Y}_{12}$ antagonist developed by AstraZeneca under the trade name Brilinta $^{\circledR}$ (Figure 1). It was approved by the FDA in 2011 for the prevention of platelet aggregation after the occurrence of a thrombotic event. ${ }^{1}$ Sales in 2015 were $\$ 619$ million and are projected to go as high as $\$ 3.5$ billion by $2023 .^{2-3}$ Most of the patented syntheses of ticagrelor use a key chiral cyclopropane intermediate, $(1 R, 2 S)-2-(3,4-$

difluorophenyl)cyclopropan-1-amine (2). The various methods reported for the preparation of this building block are lengthy, requiring resolutions, chiral auxiliaries or expensive catalysts to obtain the desired enantiomer. ${ }^{4-18}$ Recently, there has been a push to use biocatalysts in order to decrease toxic wastes and make pharmaceutical production 'greener'. ${ }^{19-20}$ A notable example of success in the development of biocatalytic alternatives can be found in Merck's production of sitagliptin, used to treat Type 2 diabetes. Directed evolution was used to engineer a transaminase to synthesize the drug under industrial process conditions; the result was a biocatalytic process with 10-13\% higher product yield, a $19 \%$ reduction in overall waste, and elimination of all heavy metals. ${ }^{21}$ Similarly, biocatalysis can potentially offer very high selectivity and environmentally friendly process conditions for the synthesis of ticagrelor. Turner and coworkers recently examined three complementary biocatalytic routes for the preparation of cyclopropylamine $2 .{ }^{22}$ They demonstrated that a ketoreductase could convert 1-(3,4-difluorophenyl)-3-nitropropan-1-one to the corresponding enantiopure alcohol, a building block that could lead to cyclopropylamine $\mathbf{2}$ in two to three steps; alternatively, a lipase or amidase could be used for kinetic resolution of a racemic mixture of cyclopropyl ester or amide to yield chiral precursors suitable for the preparation of $\mathbf{2}$.

Recent reports from our laboratory ${ }^{23-24}$ and others ${ }^{25-26}$ have shown that heme proteins can catalyze the cyclopropanation of various olefins using diazo compounds. Cyclopropyl motifs are present in many bioactive and synthetic compounds and serve as versatile intermediates in organic synthesis. ${ }^{27-28}$ The proteins reported to catalyze olefin cyclopropanation have proven to be amenable to directed evolution for increased activity and to obtain the desired product with high diastereo- and enantioselectivity in a single step: for example, Wang et al. engineered a cytochrome $\mathrm{P} 450$ to produce the chiral cyclopropane core of levomilnacipran. ${ }^{24}$

Here we report an enantioselective synthesis of the chiral cyclopropane core of ticagrelor (Figure 1C) using a whole-cell biocatalyst expressing an engineered heme protein derived from Bacillus subtilis group II truncated hemoglobin (UniProt ID: O31607). ${ }^{29}$ This engineered enzyme catalyzes the cyclopropanation of commercially available 3,4difluorostyrene (DFS, 3) using ethyl diazoacetate (EDA, 4) to provide one-step access to ethyl-(1R,2R)-2-(3,4-difluorophenyl)-cyclopropanecarboxylate $(R, R)-\mathbf{5}$, an ester precursor of the ticagrelor cyclopropylamine 2 , with excellent selectivity for the desired stereoisomer.

We began by screening various heme proteins for their ability to catalyze the reaction of DFS (3) with EDA (4) to produce the ticagrelor cyclopropyl ester $(R, R)-5$. Most of the proteins tested, such as the $\mathrm{H} 64 \mathrm{~V}$ V68A variant of sperm whale myoglobin, ${ }^{25}$ gave primarily the opposite enantiomer of the desired precursor. Three proteins gave an enantioenriched product with the desired $(R, R)$-configuration: 
B. subtilis group II truncated globin, Hydrogenobacter thermophilus cytochrome $c$ M59A Q62A, and Bacillus megaterium P450-BM3 T268A C400H, which gave product in 34, 44, and $8 \%$ ee, respectively. Mutagenesis was performed on all three proteins, but substantial improvement in enantioselectivity was only observed with variants of the $B$. subtilis group II truncated globin. The directed evolution strategy we used to optimize the performance of this protein is outlined below. B. subtilis group II truncated globin is a small (132 residues, $15 \mathrm{kDa}$ ) monomeric protein with very high oxygen affinity and a published crystal structure (PDB ID: 1UX8). ${ }^{29}$ We hypothesized that iron-carbenoid formation occurred in the distal region of the heme and that mutation of amino acid residues in this nascent "active site" could improve its catalytic performance. Bordeaux et al. showed that mutations at H64 and V68 in sperm whale myoglobin could tune the stereoselectivity of the cyclopropanation reaction between ethyl diazoacetate and styrene. ${ }^{25}$ We chose the analogous residues in $B$. subtilis truncated globin (T45 and Q49, based on a sequence alignment, see Supplemental Information) and targeted those two sites for mutagenesis (Figure 2). The two residues were mutated simultaneously to one of three residues (leucine, phenylalanine, and alanine) in an attempt to find variants that would improve the yield and enantioselectivity of the reaction. The T45A Q49A double mutant stood out as highly selective, yielding the desired product in $95 \%$ ee with a yield of 57\%. Modeling with a Dunbrack rotamer library ${ }^{30}$ suggests that the amount of space in the nascent active site is increased when the polar and larger threonine and glutamine are mutated to smaller, non-polar alanine.

Truncated globins natively bind oxygen and do not have an active site for catalysis; we attribute the observed improvement in selectivity to the formation of a binding pocket on the distal side of the heme, which presumably binds the substrates in an orientation that favors formation of the desired product. To further improve enantioselectivity, site-saturation mutagenesis was performed at position A45, and the distal heme ligand Y25. While mutations at A45 failed to improve enantioselectivity, screening of the Y25 library led to the discovery of variant Y25L T45A Q49A, which maintained the yield of the parent protein while affording >99\% dr and 97\% ee at $20 \mathrm{mM}$ DFS and $40 \mathrm{mM}$ EDA.

To further increase product yield, the Y25L T45A Q49A variant was expressed in two $E$. coli BL21 derivative cell lines C41(DE3) and C43(DE3), which have been optimized to overexpress mildly toxic proteins. ${ }^{31}$ Both $\mathrm{C} 41$ (DE3) and C43(DE3) cells expressing the Y25L T45A Q49A variant showed increases in enantio- and diastereoselectivity through improved expression of the recombinant protein. The engineered protein now effectively outcompetes the small amount of background reaction from the cells (which produces racemic product). ${ }^{32}$ The $\mathrm{C} 43$ (DE3) line displayed the highest diastereo- and enantioselectivity (>99\% dr and ee) at $20 \mathrm{mM} \mathrm{DFS} / 40 \mathrm{mM}$ EDA and was selected for use in preparative-scale reactions.

Preparative scale $(0.4 \mathrm{mmol}, 20 \mathrm{~mL})$ reactions were performed anaerobically ${ }^{23-24}$ using whole-cell catalyst $\left(\mathrm{OD}_{600}=80\right)$ and $20 \mathrm{mM}$ DFS/40 mM EDA (Figure 3). Initially these reactions were done with simultaneous addition of the bacterial catalyst and reagents, which gave high selectivity for the desired product, but only $\sim 50 \%$ yield. After testing a range of reaction conditions, we found that slow addition of the whole-cell catalyst and EDA (4) solutions to DFS (3) over the course of 3 hours gave the ticagrelor cyclopropyl ester $(R, R)-5$ 
as virtually a single isomer (>99\% dr, 98\% ee) in $79 \%$ yield (see Supporting Information). It is likely that slow addition slows down the formation of EDA dimer and reduces catalyst inactivation by carbene transfer to the protein (heme cofactor and nucleophilic side chains) rather than the DFS, an inactivation mechanism we recently analyzed in detail in another cyclopropanation enzyme. ${ }^{33}$

This work has generated an efficient, stereoselective, and potentially low-cost bacterial biocatalyst for producing the cyclopropane precursor to the antithrombotic agent ticagrelor. The ester product of the biocatalytic reaction $(R, R)-\mathbf{5}$, can be converted easily to the amine ticagrelor precursor 2 via ammonolysis followed by Hofmann rearrangement ${ }^{16}$ of the corresponding amide or a Curtius rearrangement ${ }^{9}$ on the corresponding acyl azide. This work has also demonstrated how directed evolution can rapidly optimize a newly discovered enzyme activity, olefin cyclopropanation, to achieve desired product selectivity and yield. With careful process optimization, processes based on biological catalysts such as reported here can continue to replace far less environmentally friendly methods for producing pharmaceutical intermediates.

\title{
Supplementary Material
}

Refer to Web version on PubMed Central for supplementary material.

\section{Acknowledgments}

Funding sources

This work was supported in part by the National Science Foundation, Office of Chemical, Bioengineering, Environmental and Transport Systems SusChEM Initiative (grant CBET-1403077) and the Defense Advanced Research Projects Agency Biological Robustness in Complex Settings Contract HR0011-15-C-0093. Funding for this work to Provivi, Inc. from the National Science Foundation under Phase 1 STTR Grant 1549855 is also gratefully acknowledged. R.D.L. is supported by NIH/NRSA training grant (5 T32 GM07616). Any opinions, findings, and conclusions or recommendations expressed in this material are those of the author(s) and do not necessarily reflect the views of the funding organizations.

We thank Dr. S. Virgil and the Center for Catalysis and Chemical Synthesis (3CS) at Caltech for assistance with the SFC.

\section{ABBREVIATIONS}

\author{
EDA ethyl diazoacetate \\ DFS 3,4-difluorostyrene
}

\section{References}

1. Wijeyeratne YD, Joshi R, Heptinstall S. Expert Rev Clin Pharmacol. 2012; 5:257-269. [PubMed: 22697589]

2. AstraZeneca. [accessed Aug 24, 2016] Full-Year and Q4 2015 Results (press release). Feb 4. 2016 https://www.astrazeneca.com/media-centre/press-releases/2016/full-year-and-q4-2015results-04022016.html

3. AstraZeneca. [accessed Aug 24, 2016] AstraZeneca Issues Update on Strategy to Deliver Value to Shareholders (press release). May 6. 2014 https://www.astrazeneca.com/media-centre/pressreleases/2014/astrazeneca-updated-strategy-value-for-shareholders-06052014.html 
4. Guile, S., Hardern, D., Ingall, A., Springthorpe, B., Willis, P. Novel Triazolo(4,5-d)pyrimidine Compounds. WO. 0034283. Jun 15. 2000

5. Guile, S., Springthorpe, B. Novel [1,2,3]-Triazolo[4,5-d]pyrimidine Compounds. WO. 2001036421 A1. May 25. 2001

6. Larsson, U., Magnusson, M., Musil, T., Palmgren, A. Novel Triazolo Pyrimidine Compounds. WO. 0192263. Dec 6. 2001

7. Clark, A., Jones, E., Larsson, U., Minidis, A. Process for the Preparation of Cyclopropyl Carboxylic Acid Esters and Derivatives. US Patent. 7,122,695 B2. Oct 17. 2006

8. Springthorpe B, Bailey A, Barton P, Birkinshaw TN, Bonnert RV, Brown RC, Chapman D, Dixon J, Guile SD, Humphries RG, Hunt SF, Ince F, Ingall AH, Kirk IP, Leeson PD, Leff P, Lewis RJ, Martin BP, McGinnity DF, Mortimore MP, Paine SW, Pairaudeau G, Patel A, Rigby AJ, Riley RJ, Teobald BJ, Tomlinson W, Webborn PJ, Willis PA. Bioorg Med Chem Lett. 2007; 17:6013-6018. [PubMed: 17827008]

9. Mitsuda, M., Moroshima, T., Tsukuya, K., Watabe, K., Yamada, M. A Process for the Preparation of Optically Active Cyclopropylamines. WO. 2008018823 A1. Feb 14. 2008

10. Dejonghe, J-P., Peeters, K., Renard, M. Chemical Process for the Preparation of Aromatic Cyclopropane Esters and Amides. WO. 2008018822 A1. Feb 14. 2008

11. Aufdenblatten, R., Bohlin, MH., Hellstroem, H., Johansson, PW., Larsson, UG., Recknagel, M., Weiss, U. A Process for Preparing [1S-[1-alpha, 2-alpha, 3-beta (1S*, 2R*) 5-beta] ]-3-[7-[2-(3, 4Difluorophenyl) -cyclopropylamino]-5-(propylthio)-3H-1, 2, 3-triazolo[4, 5-d]pyrimidin-3-yl]-5(2-hydroxyethoxy)cyclopentane-1, 2-diol and to its Intermediates. WO. 2010030224 A1. Mar 18. 2010

12. Dejonghe, J-P., Peeters, K., Renard, M. Chemical Process for Preparation of Intermediates. US Patent. 7,863,469 B2. Jan 4. 2011

13. Khile, AS., Patel, J., Trivedi, N., Pradhan, NS. Novel Process for Preparing Phenylcyclopropylamine Derivatives Using Novel Intermediates. WO. 2011132083 A3. Oct 27. 2011

14. Khile, AS., Nair, V., Trivedi, N., Pradhan, NS. Novel Processes for the Preparation of Phenylcyclopropylamine Derivatives and Use thereof for Preparing Ticagrelor. WO. 2012001531 A2. Jan 5. 2012

15. Zhang H, Liu J, Zhang L, Kong L, Yao H, Sun H. Bioorg Med Chem Lett. 2012; 22:3598-3602. [PubMed: 22546677]

16. Sterk, D., Zupancic, B. Synthesis of 2-(3,4-Difluorophenyl)cyclopropanecarboxylic Acid. WO. 2013124280 A1. Aug 29. 2013

17. Ding HX, Liu KKC, Sakya SM, Flick AC, O'Donnell CJ. Bioorg Med Chem. 2013; 21:2795-2825. [PubMed: 23623674]

18. Shinde GB, Mahale PK, Padaki SA, Niphade NC, Toche RB, Mathad VT. Springerplus. 2015; 4:493-504. [PubMed: 26389018]

19. Pollard DJ, Woodley JM. Trends Biotechnol. 2007; 25:66-73. [PubMed: 17184862]

20. Dunn PJ. Chem Soc Rev. 2012; 41:1452-1461. [PubMed: 21562677]

21. Savile CK, Janey JM, Mundorff EC, Moore JC, Tam S, Jarvis WR, Colbeck JC, Krebber A, Fleitz FJ, Brands J, Devine PN, Huisman GW, Hughes GJ. Science. 2010; 329:305-309. [PubMed: 20558668]

22. Hugentobler KG, Sharif H, Rasparini M, Heath RS, Turner NJ. Org Biomol Chem. 2016; 14:80648067. [PubMed: 27470519]

23. Coelho PS, Brustad EM, Kannan A, Arnold FH. Science. 2013; 339:307-310. [PubMed: 23258409]

24. Wang ZJ, Renata H, Peck NE, Farwell CC, Coelho PS, Arnold FH. Angew Chem Int Ed. 2014; 53:6810-6813.

25. Bordeaux M, Tyagi V, Fasan R. Angew Chem Int Ed. 2015; 54:1744-1748.

26. Gober JG, Rydeen AE, Gibson-O'Grady EJ, Leuthaeuser JB, Fetrow JS, Brustad EM.

ChemBioChem. 2016; 17:394-397. [PubMed: 26690878]

27. Chen DYK, Pouwer RH, Richard JA. Chem Soc Rev. 2012; 41:4631-4642. [PubMed: 22592592] 
28. Reissig HU, Zimmer R. Chem Rev. 2003; 103:1151-1196. [PubMed: 12683780]

29. Giangiacomo L, Ilari A, Boffi A, Morea V, Chiancone E. J Biol Chem. 2005; 280:9192-9202. [PubMed: 15590662]

30. Dunbrack RL, Karplus M. J Mol Biol. 1993; 230:543-574. [PubMed: 8464064]

31. Miroux B, Walker JE. J Mol Biol. 1996; 260:289-298. [PubMed: 8757792]

32. Weissenborn MJ, Löw SA, Borlinghaus N, Kuhn M, Kummer S, Rami F, Plietker B, Hauer B. ChemCatChem. 2016; 8:1636-1640. 
(A)

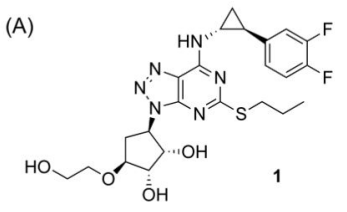

(C)

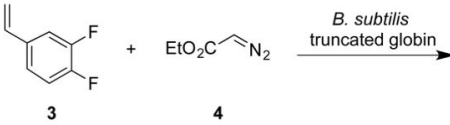

(B)
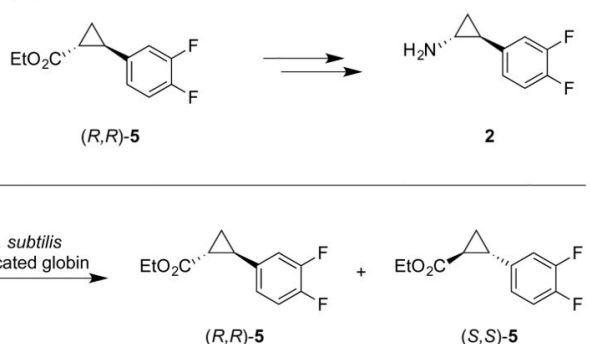

Figure 1.

(A) Structure of ticagrelor 1. (B) The cyclopropyl ester precursor $\mathbf{5}$ can be converted to the cyclopropylamine precursor $\mathbf{2}$ by making the acyl azide and performing a Curtius rearrangement ${ }^{9}$ or via ammonolysis followed by Hofmann rearrangement ${ }^{16}$ of the corresponding amide. (C) Cyclopropanation of 3,4-difluorostyrene (3) with ethyl diazoacetate (4) catalyzed by engineered heme protein makes the cyclopropyl ester 5 . 


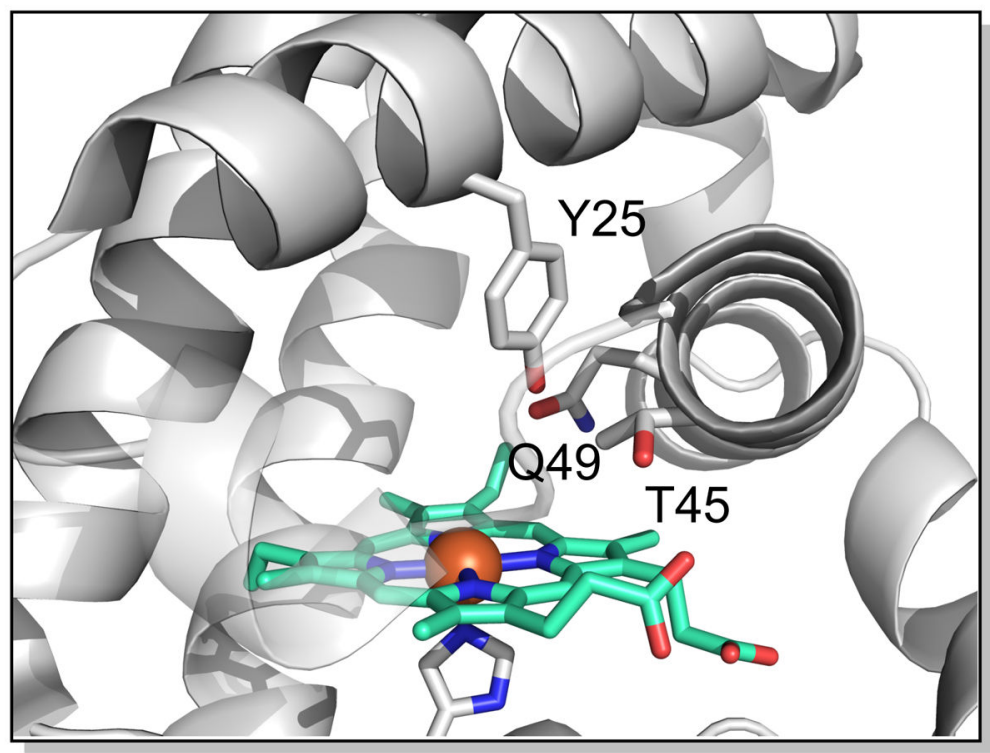

Figure 2.

Positions of the Y25, T45, and Q49 residues near the heme iron in the B. subtilis wild-type protein (PDB ID: 1UX8). 

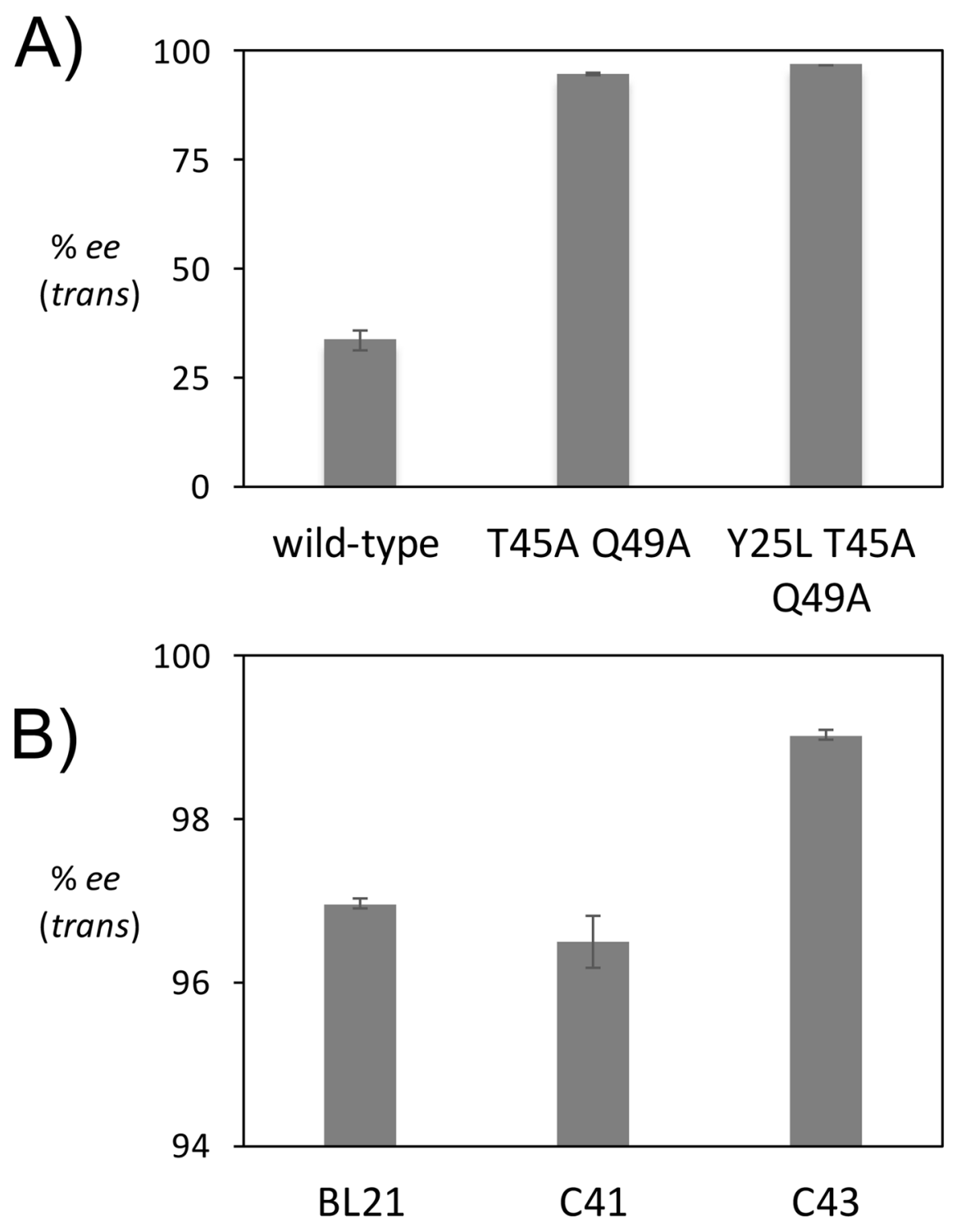

Figure 3.

(A) Enantioselectivity of the cyclopropanation reaction catalyzed by various $B$. subtilis variants. Reaction conditions: $\mathrm{OD}_{600}=60,20 \mathrm{mM}$ DFS $/ 40 \mathrm{mM}$ EDA. (B) Enantioselectivity of the cyclopropanation reaction catalyzed by B. subtilis T45A Q49A Y25L expressed in various $E$. coli strains. Reaction conditions: $\mathrm{OD}_{600}=60,20 \mathrm{mM}$ DFS $/ 40 \mathrm{mM}$ EDA. The error bars represent standard deviation of \% ee (trans) for the reactions run in triplicate. 